\title{
QUALITY ASPECTS OF FRUIT AND VEGETABLES DRIED CONVECTIVELY WITH OSMOTIC PRETREATMENT
}

\author{
Stefan J. Kowalski ${ }^{*}$ Joanna M. Łechtańska, Justyna Szadzińska \\ Poznan University of Technology, Institute of Technology and Chemical Engineering, \\ Pl. Marii Skłodowskiej Curie 2, 60-965 Poznań, Poland
}

\begin{abstract}
This article presents a quality analysis of convectively dried fruits and vegetables with preliminary osmotic dehydration. Tests were carried out on banana fruit and red beetroot samples. Hypertonic solutions of fructose for the banana and those of sucrose for the red beetroot were used, each one at three different concentrations. After osmotic dewatering treatment conducted at different time intervals and after osmotic dehydration the samples were dried convectively until an equilibrium with the surroundings was attained. Osmotic dehydration and convective drying curves were determined. The values of Solids Gain (SG), Water Loss (WL) and Weight Reduction (WR) were measured and changes in the samples' colour and shape after convective drying with and without osmotic pretreatment were assessed.
\end{abstract}

Keywords: osmotic dehydration, convective drying, banana, red beetroot, drying kinetics, product quality

\section{INTRODUCTION}

Fresh vegetables and fruits serve as important and indispensable sources of vitamins and minerals such as calcium, phosphorus, iron and many other constituents. However, most vegetables and fruits contain more than $80 \%$ water and therefore are highly perishable (Pabis and Jaros, 2002). Because of putrefaction processes, long-term storage of fresh vegetables and fruits is not possible (Kowalski and Mierzwa, 2011; Mujumdar, 2007). One of the ways of their preservation is to convert perishable food into stabilised products, and thus to enable their storage for extended periods of time and to reduce their postharvest losses.

Drying is one of the ways to ensure long lasting durability of these products (Nastaj and Witkiewicz, 2004; Pabis, 1999). Osmotic dehydration $(O D)$ as a pretreatment process before proper drying enables moisture removal from vegetables and fruits up to $50 \%$. Besides, the application of osmotic pretreatment considerably reduces chemical, physical and biological adverse changes which occur during long lasting convective drying, called hot air drying (Kowalska and Lenart, 2001; Pakowski and Adamski, 2007; Piasecka et al., 2012; Witrowa-Rajchert and Rząca, 2009).

Osmotic dehydration relies upon diffusion of water from food product immersed in a hypertonic solution characterised with a high osmotic pressure. It is mostly an aqueous solution of salt or sugar agent (Chua et al., 2004). Osmotic dewatering does not remove water totally but only a part of it. Therefore, further drying of these products is necessary. However, osmotic pretreatment is effective in energy saving and first of all in improvement of the final quality of dried products (Kowalski et al., 2009; Sagar and Kumar, 2010). 
Recent research shows that fruits and vegetables subjected to osmotic pretreatment significantly improve drying characteristics adverse changes during drying are minimised and finally longer storage of these products is possible. Osmotic pretreatment helps to preserve better aroma, flavour, colour attributes, and can provide products with higher antioxidant activity. The $O D$ rate depends on the kind of processed material, the size of pores, the kinds of osmotic solution and its concentration, temperature, and dehydration time (Kowalska and Lenart, 2001). This treatment, however, precipitates and crystallises solute in pores causing, (sometimes desirable) flavour and fragrance changes and does not bring total drying time reduction (Mujumdar and Law, 2010).

The purpose of this work is to study the influence of $O D$ of banana and red beetroot samples on their final quality after subsequent convective drying. A water solution of fructose for the banana and a water solution of sucrose for the beetroot were used as hypertonic solutions, each one at three different concentrations: $20 \%, 35 \%$ and $50 \%$. The dewatering times were selected to be: $30,60,90$ minutes. After osmotic dehydration the samples were subsequently dried convectively until an equilibrium with the surroundings was achieved. $O D$ curves and convective drying curves were determined and the values of Solids Gain (SG), Water Loss (WL) and Weight Reduction (WR) were measured. Changes in the samples' colour, shape and general appearance were analysed to assess the final product quality.

\section{MATERIALS AND METHODS}

Red beetroot is a source of nutrients such as vitamins A and C, carotenoids, flavonoids, betanin, saponins, soluble and insoluble dietary fiber and antioxidants. Although it is a very sweet vegetable, containing more sugar than the sweet corn or carrot, the content of sugar in the beetroot does not exceed 10\% (Figiel, 2010; Manivannan and Rajasimma, 2009). This vegetable is widely used in industrial production as a natural red food colourant. The red pigment of the beetroot is known as betalain (Glokhale and Lele, 2011), and is used to improve the red colour of tomato pastes, soups, desserts, jams, sweets, ice creams, cereals, etc. The red beetroot is also applied in medicine to improve digestion, blood quality (Glokhale and Lele, 2012) and antimicrobial activity (Longinova et al., 2011). The consumption of red beetroots, similarly like carrots, cauliflowers, cabbages, onions and other vegetables, is associated with a lower risk of cancer, especially of the breast, rectum and tongue (Patkai et al., 1997; Potter, 1997). Dehydrated red beetroot can be consumed also in the form of chips or after a special preparation as a component of instant food (Figiel, 2010).

Banana is one of the most significant fruits in the world, being cultivated in almost all tropical countries. It is rich in valuable compounds, especially vitamins $\mathrm{A}$ and $\mathrm{C}$, calcium, potassium, magnesium and sodium. Banana is also a source of energy because of high sugar content (Fernandes et al., 2006). During banana ripening the starch transforms into sugar. This process involves enzymes including sucrose phosphate and sucrose synthesis which are responsible for sucrose accumulation in banana fruit ( $\mathrm{Li}$ et al., 2011). Banana could be processed into a variety of products, especially chips, powder, etc. Dehydration and drying are the most important conservation processes that are widely practised for banana because of savings made in packaging and storage (Chavan et al., 2010).

Fresh bananas (Musa paradisica L.) and red beetroots (Beta vulgaris L.) bought at a local market were used for tests. Each red beetroot bulb was cleaned, peeled and cut into circular disks $50 \mathrm{~mm}$ in diameter and $3 \mathrm{~mm}$ thickness. Fully ripe and yellowish coloured bananas were hand peeled and cut into slices of $8 \mathrm{~mm}$ thickness, as proposed by Kadam and Dhingra (2009), who revealed that the best results from banana convective drying were gained when the thickness of the slices was $8 \mathrm{~mm}$. 


\subsection{Experimental Procedure}

The samples were weighed and then immersed in respective hypertonic solutions of three different concentration $20 \%, 35 \%$ and $50 \%$. The immersion periods in the osmotic solutions were different and amounted to 30,60 and 90 minutes. During osmotic dewatering the samples were pulled out from the osmotic solutions every 10 minutes and weighed. Next, at the end of osmotic dehydration, the samples were weighed and transported to a dryer chamber for convective drying. The time of drying lasted until the samples attained an equilibrium with the surroundings at given drying conditions. The banana samples were dried in the convective dryer presented in Figure 1, and the beetroot samples were dried in the hybrid dryer shown in Figure 2.

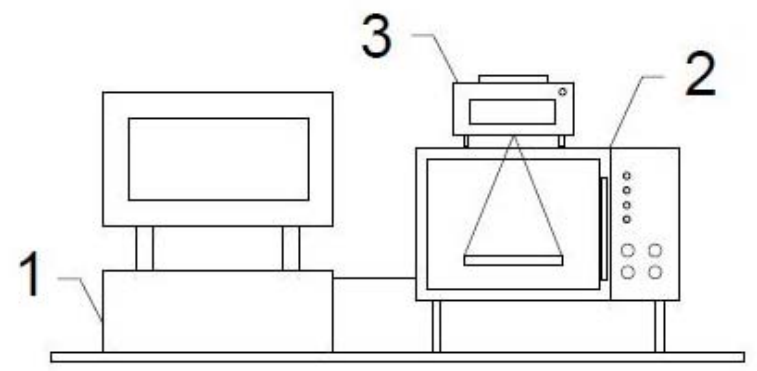

Fig. 1. Scheme of drying system for banana material; 1 - personal computer, 2 - chamber dryer, 3 - balance

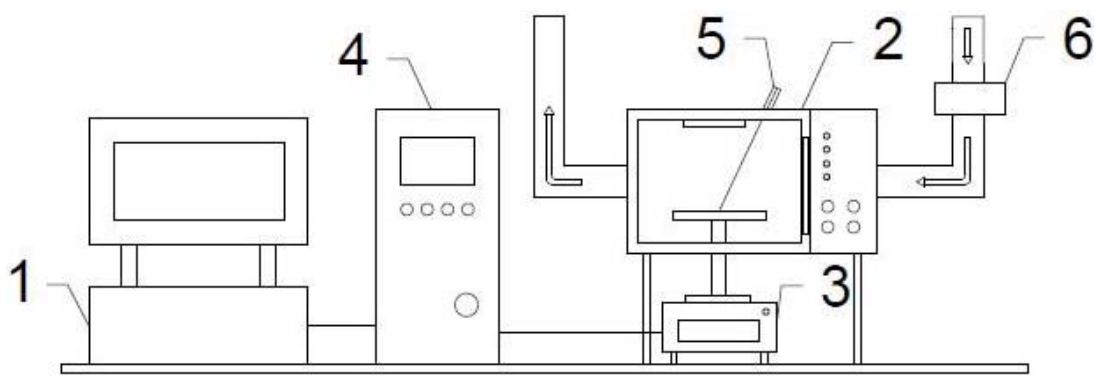

Fig. 2. Scheme of drying system for red beetroot material;

1 - personal computer, 2 - chamber dryer, 3 - balance, 4 - driver unit, 5 - pyrometer, 6 - air system (electric heater and fan)

Both tested materials were dried convectively at $65^{\circ} \mathrm{C}$, which can be considered optimal for fruits and vegetables (Jayaraman and Das Gupta, 2007). The mass of the samples was measured continuously on line during drying process in both cases. When the samples achieved a thermodynamic equilibrium with the surroundings their mass became constant. In order to estimate the mass of totally dry samples, the samples were weighted and subjected to further convective drying at $70^{\circ} \mathrm{C}$ for 24 hours in another chamber dryer SML42/250/M produced by Zalmed (Poland). The tests of convective drying of the samples without preliminary osmotic dehydration were also carried out. Every experiment was repeated at least three times.

\subsection{Determination of Moisture Content (MC)}

The initial mass of each tested sample $m_{i}$ was determined with an accuracy of $0.01 \%$ using the moisture analyser model XM120 produced by Precisa (Switzerland). During osmotic dehydration, the actual mass of each sample $m_{t}$ at time $t$ was measured. The actual moisture content $(M C)$ is expressed as the ratio of the actual moisture mass $m_{M}(t)$ and the initial mass of the sample $m_{i}$, that is: 


$$
M C(t)=\frac{m_{M}(t)}{m_{i}}=\frac{m_{t}(t)-m_{d}}{m_{i}}
$$

where $m_{t}(t)$ is the actual total sample mass, $m_{i}$ is the initial mass of the sample, and $m_{d}$ is the mass of a dry sample, that is, the mass of the sample's solids without osmotic dehydration.

\subsection{Characteristic Parameters of Osmotic Dehydration}

The effect of osmotic dehydration is determined by three parameters: the Solids Gain $(S G)$, which gives the mass of an insoluble substance that was diffused from the hypertonic solution to the processed material, the Weight Reduction (WR) - a parameter which describes changes of the sample mass before and after osmotic dehydration, and the Water Loss $(W L)$ - a parameter, which presents the amount of water loss by processed material due to osmotic dehydration. These parameters are expressed by the following formulas (Manivannan and Rajasimman, 2009):

$$
\begin{aligned}
& W R=\frac{m_{i}-m_{0}}{m_{i}} \\
& S G=\frac{M-m_{d}}{m_{i}} \\
& W L=S G+W R
\end{aligned}
$$

where $m_{0}$ is the sample mass after osmotic dehydration, and $M$ is the mass of sample solids after osmotic dehydration, that is, it may contain also a portion of diffusive solid mass gained from the hypertonic solution.

\subsection{Quality Assessment of Dried Products}

A visual assessment of the product quality after drying was done using the human sense and on the basis of photos taken before and after osmotic dehydration and after the final convective drying. Changes of sample surface colour were measured by Konica Minolta CR400 colorimeter and expressed in CIE Lab colour space of $0.01 \%$ precision. The colorimeter measurements were done in five randomly chosen spots, and in every spot five measurements of $\left(L^{*}, a^{*}, b^{*}\right)$ parameters were made (Fig. 3).

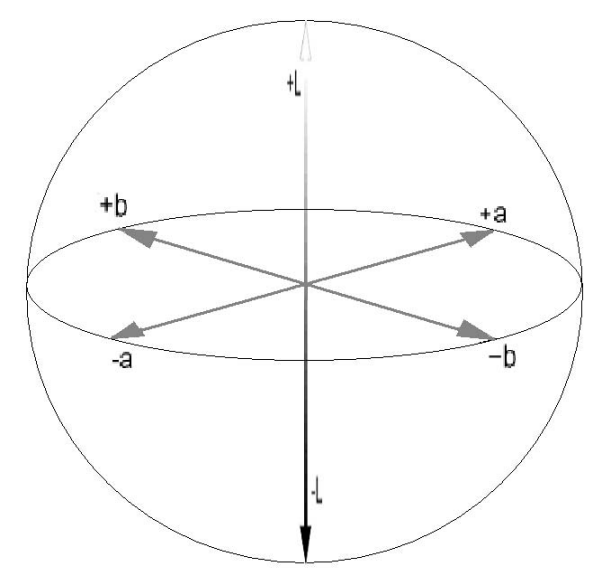

Fig. 3. CIE Lab colour space 
To avoid background influence, every measurement was done on a white ceramic plate. The arithmetic averages of colour parameters were taken to the final calculations. The colour parameters measured after the osmotic dehydration and after the convective drying were referred to the colours of fresh samples. Next, the resultant colour change $\Delta E$ was calculated using the formula:

$$
\Delta E=\sqrt{\Delta L^{* 2}+\Delta a^{* 2}+\Delta b^{* 2}}
$$

where $\Delta L^{* 2}=L_{p}^{*}-L_{s}^{*}, \Delta a^{* 2}=a_{p}^{*}-a_{s}^{*}, \Delta b^{* 2}=b_{p}^{*}-b_{s}^{*}$ present the difference between black and white, red and green, and yellow and blue, and subscripts $p$ and $s$ refer to pattern and to sample respectively.

\section{RESULTS AND DISCUSSION}

\subsection{Osmotic Dehydration}

The curves in Figure 4 present reduction of moisture content $M C(t)$ in time during osmotic dehydration $(O D)$ in a hypertonic solution of three different concentrations for 30,60 and 90 min respectively.
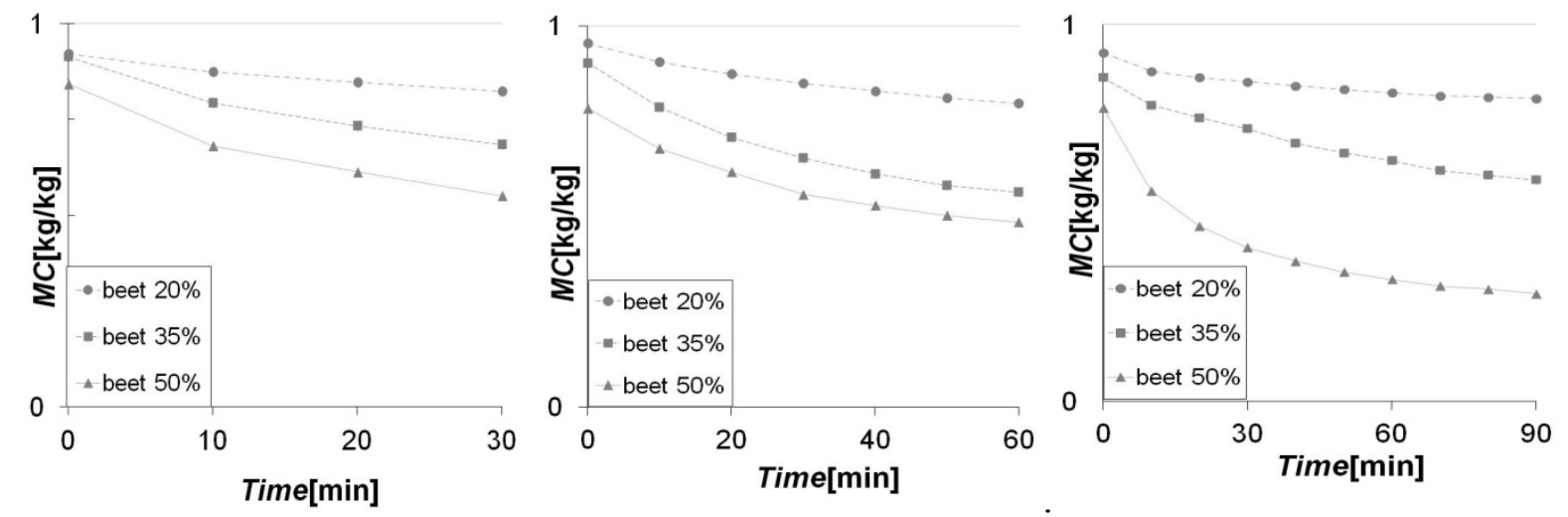

Fig. 4. Kinetics of the osmotic dewatering process for red beetroot

It follows from the above dewatering curves that the concentration of the hypertonic sucrose solution influences significantly the kinetics of osmotic dehydration. A high concentration of the osmotic solution causes a high dehydration rate. The final $M C$ is different for several processes and depends both on the dehydration time and on the concentration of the osmotic solution. The smallest final value of the $M C$ was obtained for $50 \%$ solution concentration and 90 minutes dewatering time. However, even in this process the sample did not achieve the equilibrium state after 90 minutes of $O D$. Then, a further reduction of the moisture content was still possible in this hypertonic solution.

The characteristic parameters for $O D$ expressed by Equations (2) to (4) are collected in Table 1. They enable a comparison of $O D$ effects concerning moisture reduction and diffusive solid gain in several dewatering processes. The data show clearly how much the solution concentration $(S C)$ and longer dewatering time influence the decrease of water amount in a sample. This effect is expressed by the $W L$ parameter. The $S G$ parameter increases significantly with both the $S C$ and the $O D$ time. They point out how much of the insoluble substances diffused from the solution to the sample. The rate of total sample mass decreases with an increase of the $S C$ and $O D$ time is expressed by the $W R$ parameter.

It can be seen that the moisture content decreases with an increasing osmotic $S C$. However, the differences are not so significant as in the case of the red beetroot samples dehydrated in the sucrose solution. The $M C$ decreases also with the length of the $O D$ time. The third graph shows that for the 
time of $90 \mathrm{~min}$ the equilibrium state for moisture is not stabilised yet, so the process could be continued.

Table 1. Osmotic dehydration parameters for red beetroot materials

\begin{tabular}{|c|c|c|c|c|c|c|c|c|c|}
\hline Time $O D$ & \multicolumn{3}{|c|}{$30 \mathrm{~min}$} & \multicolumn{3}{c|}{$60 \mathrm{~min}$} & \multicolumn{3}{c|}{$90 \mathrm{~min}$} \\
\hline$S C[\%]$ & 20 & 35 & 50 & 20 & 35 & 50 & 20 & 35 & 50 \\
\hline$W R[\%]$ & 10.08 & 14.71 & 29.47 & 13.08 & 22.83 & 41.30 & 5.91 & 21.33 & 47.54 \\
\hline$S G[\%]$ & 0.47 & 1.99 & 7.45 & 0.62 & 2.83 & 7.53 & 1.56 & 6.36 & 7.70 \\
\hline$W L[\%]$ & 10.54 & 16.70 & 36.92 & 13.71 & 25.67 & 48.83 & 7.47 & 27.68 & 55.25 \\
\hline
\end{tabular}

Changes in the $M C$ during the $O D$ of the banana samples at different concentrations of the fructose solution and dewatering time are demonstrated in Figure 5.
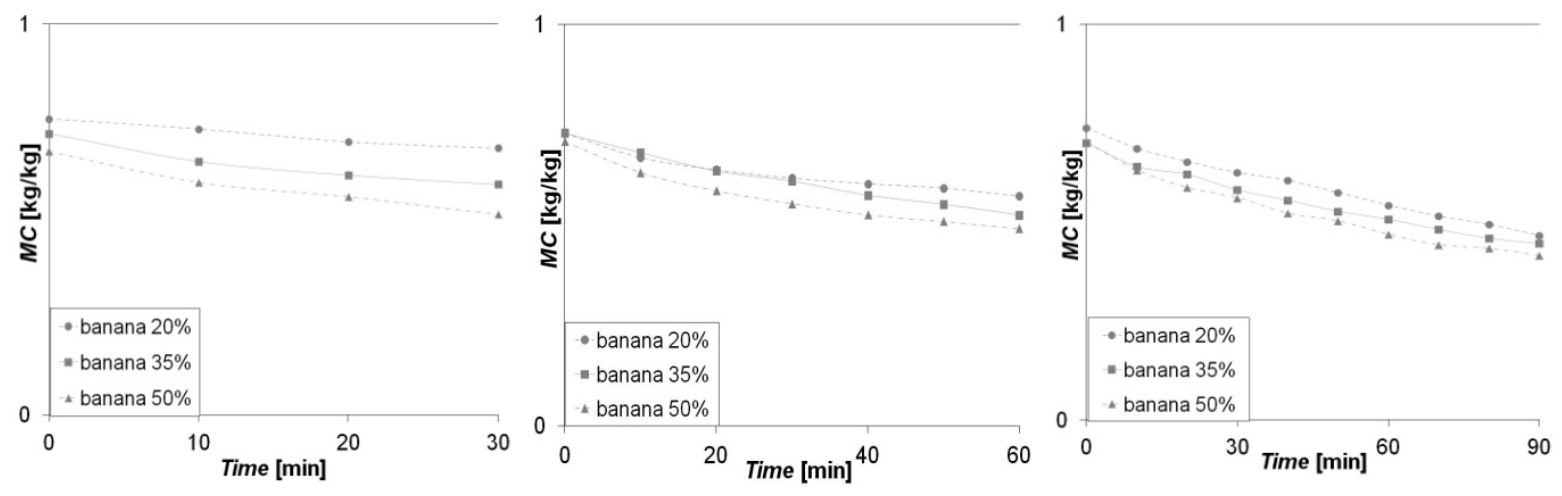

Fig. 5. Kinetics of the osmotic dewatering process for banana

The osmotic parameters for the banana dehydration i.e. $W R, S G, W L$ for different $S C$ and the $O D$ time are presented in Table 2 .

Table 2. Osmotic dehydration parameters for banana materials

\begin{tabular}{|c|c|c|c|c|c|c|c|c|c|}
\hline Time $O D$ & \multicolumn{3}{|c|}{$30 \mathrm{~min}$} & \multicolumn{3}{c|}{$60 \mathrm{~min}$} & \multicolumn{3}{c|}{$90 \mathrm{~min}$} \\
\hline$S C[\%]$ & 20 & 35 & 50 & 20 & 35 & 50 & 20 & 35 & 50 \\
\hline$W R[\%]$ & 7.42 & 13.87 & 16.22 & 15.77 & 20.37 & 21.74 & 27.08 & 22.63 & 28.57 \\
\hline$S G[\%]$ & -1.77 & -0.92 & 2.96 & -1.57 & -0.89 & 3.31 & -1.38 & -0.80 & 3.93 \\
\hline$W L[\%]$ & 5.65 & 12.95 & 19.19 & 14.20 & 19.48 & 25.05 & 25.69 & 21.84 & 32.50 \\
\hline
\end{tabular}

The highest values of $W R$ and $W L$ were obtained again for $50 \% S C$ and for $90 \min O D$ time. For all $O D$ processes carried out for $20 \% S C$, independently of the osmotic dehydration time, negative values of $S G$ were obtained. This phenomenon may be explained through the loss of the banana solid mass due to diffusion of sugar to the low concentrated fructose solution. It can be a result of a higher amount of natural sugar in the banana samples than in $20 \%$ fructose solution in which the banana sample was immersed. Meneses et al. (2009) explained that banana in mature stage contains $33.3 \mathrm{~g}$ soluble substances per $100 \mathrm{~g}$ of banana mass. A constant increase of the $S G$ value with an increase of $O D$ time follows probably from the fact that after $30,60,90 \mathrm{~min}$ of $O D$ time, the thermodynamic equilibrium between the sample and the solution has not been established yet. 


\subsection{Kinetics curves of convective drying}

Figure 6 presents drying curves for the beetroot samples after convective drying with pre-osmotic dehydration, and drying curves of the fresh samples for comparison purposes.
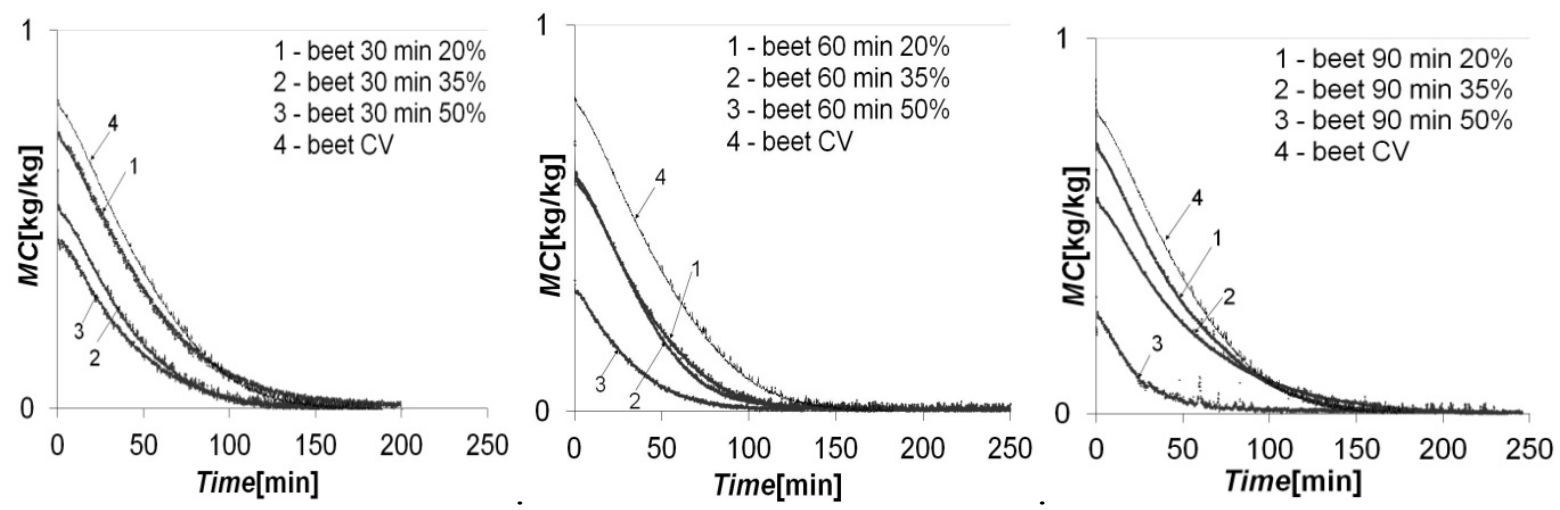

Fig. 6. Kinetics of convective drying of beetroot

It is obvious that a high concentration of the sucrose solution in the hypertonic solution and long time of $O D$ cause a great reduction of moisture content at the end of $O D$ process, which is simultaneously the initial value of moisture content for the process of convective drying. It was observed that the time of convective drying of the samples dehydrated in solutions of higher concentration was only slightly shorter than the other ones. However, the drying times of samples pre-dehydrated in solutions of lower concentration or by longer dehydration times were comparable, or even slightly longer, than the drying times of the fresh samples. It is probably the result of pore size reduction at the sample surface being a consequence of sugar molecule diffusion from the hypertonic solution.

Drying curves of the banana samples after convective drying with and without osmotic pretreatment are presented in Figure 7.
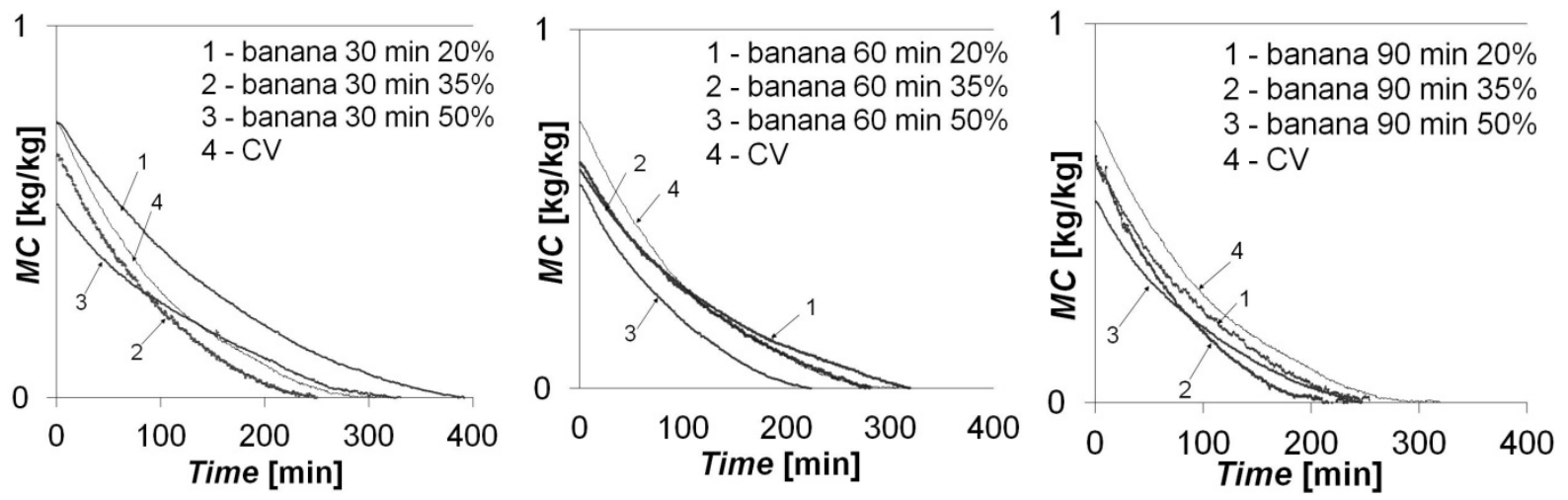

Fig. 7. Kinetics of convective drying of banana

The graphs presented in Figure 7 show that the drying times of samples with osmotic pretreatment were not significantly reduced, and in some cases they even increased in comparison to those which underwent osmotic dehydration. The shortest drying times were obtained for the samples with osmotic pretreatment in $50 \%$ solutions. Based on these graphs, it can be concluded that longer times of $O D$ do not shorten convective drying times because of the above mentioned sugar diffusion from the solution to the sample. 


\subsection{Quality of the Product}

The results of colour tests of the fresh beet root samples and those after convective drying with osmotic pretreatment by various $S C$ and different times of $O D$ are presented in Table 3.

Table 3. Colorimetric data of beet root samples

\begin{tabular}{|c|c|c|c|c|c|c|c|c|c|c|}
\hline$S C[\%]$ & \multicolumn{3}{|c|}{20} & \multicolumn{3}{c|}{35} & \multicolumn{3}{c|}{50} & \multirow{2}{*}{$C V$} \\
\cline { 1 - 8 } Time OD & $30 \mathrm{~min}$ & $60 \mathrm{~min}$ & $90 \mathrm{~min}$ & $30 \mathrm{~min}$ & $60 \mathrm{~min}$ & $90 \mathrm{~min}$ & $30 \mathrm{~min}$ & $60 \mathrm{~min}$ & $90 \mathrm{~min}$ & \\
\hline$\Delta L$ & 3.62 & 2.38 & 8.06 & 12.43 & 3.13 & 2.04 & 1.89 & 1.04 & 7.28 & 6.61 \\
\hline$\Delta a$ & -20.20 & -10.29 & -1.43 & -17.66 & -17.16 & -16.87 & -15.05 & -14.16 & -13.70 & -6.55 \\
\hline$\Delta b$ & -1.67 & 0.98 & 5.20 & 1.13 & -3.65 & -3.81 & -2.89 & -2.32 & -3.81 & -0.56 \\
\hline$\Delta E$ & $\begin{array}{c}20.59 \\
\pm 0.46\end{array}$ & $\begin{array}{c}18.60 \\
\pm 0.27\end{array}$ & $\begin{array}{c}9.69 \\
\pm 0.66\end{array}$ & $\begin{array}{c}21.62 \\
\pm 0.48\end{array}$ & $\begin{array}{c}17.82 \\
\pm 0.46\end{array}$ & $\begin{array}{c}17.42 \\
\pm 0.49\end{array}$ & $\begin{array}{c}15.44 \\
\pm 0.48\end{array}$ & $\begin{array}{c}14.38 \\
\pm 0.47\end{array}$ & $\begin{array}{c}15.98 \\
\pm 0.51\end{array}$ & $\begin{array}{c}9.32 \\
\pm 0.49\end{array}$ \\
\hline
\end{tabular}

It can be seen that an increase of dehydration time decreases the parameter $\Delta E$. However, the values of $\triangle E$ for samples with $O D$ are rather very high, higher than those without $O D$. The quantity $\triangle a$ contributes the most to colour change. This parameter presents the colour change from green to red. The red beetroot samples (Figs. 8,9) do not differ so much from each other. It follows from very small values of the parameter $\Delta L$, which corresponds to the luminosity of the sample. A little difference in $\Delta L$ means that the materials are slightly lighter than the fresh material. The lowest value of parameter $\Delta L$ was obtained for the sample dewatered osmotically for an hour in 50\% sucrose solution.

Biological materials have the proclivity to shrinking and changing shape and colour during drying. Figure 8 shows photos of the red beetroot samples after convective drying with and without prior osmotic dehydration for $90 \mathrm{~min}$ in different concentrations.

It was observed that the higher the concentration of the osmotic solution the less material changes in shape and colour are observed.
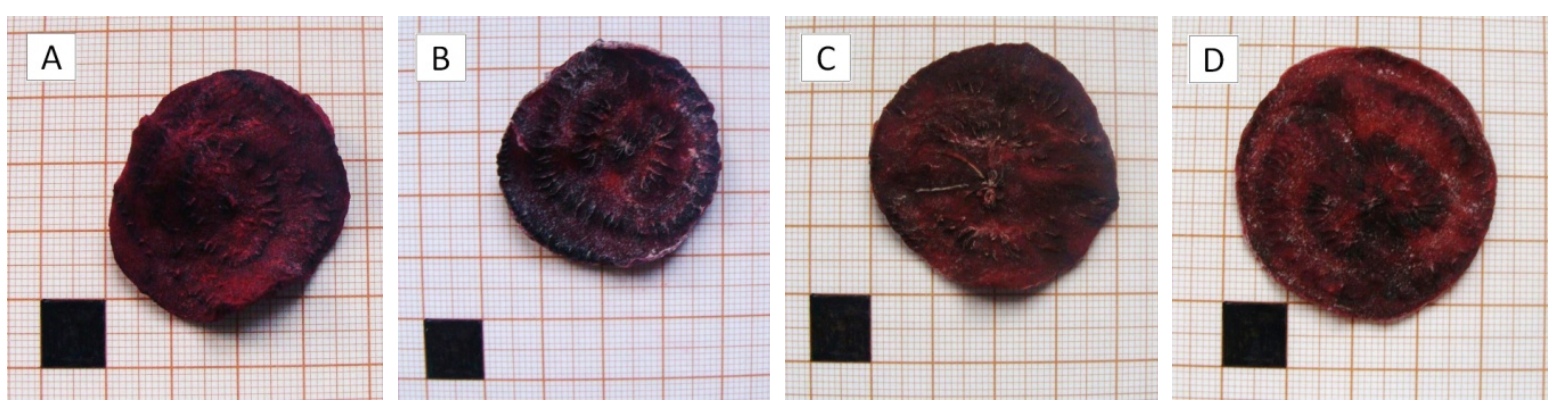

Fig. 8. Photos of red beetroot samples after convective drying with and without $O D$ for 90 min and different sucrose concentrations: A) without $O D$, B) $20 \% S C$, C) $35 \% S C$, D) $50 \% S C$

Figure 9 presents photos of the red beetroot samples taken after convective drying with and without prior osmotic dehydration in $50 \%$ solution for different dehydration times. It can be clearly seen that the longer the residence time of the beetroot sample in the osmotic solution the better sample quality is obtained.

Results of the colour measurements for the banana samples with osmotic pretreatment by various $S C$ and different times of $O D$ are listed in Table 4. 

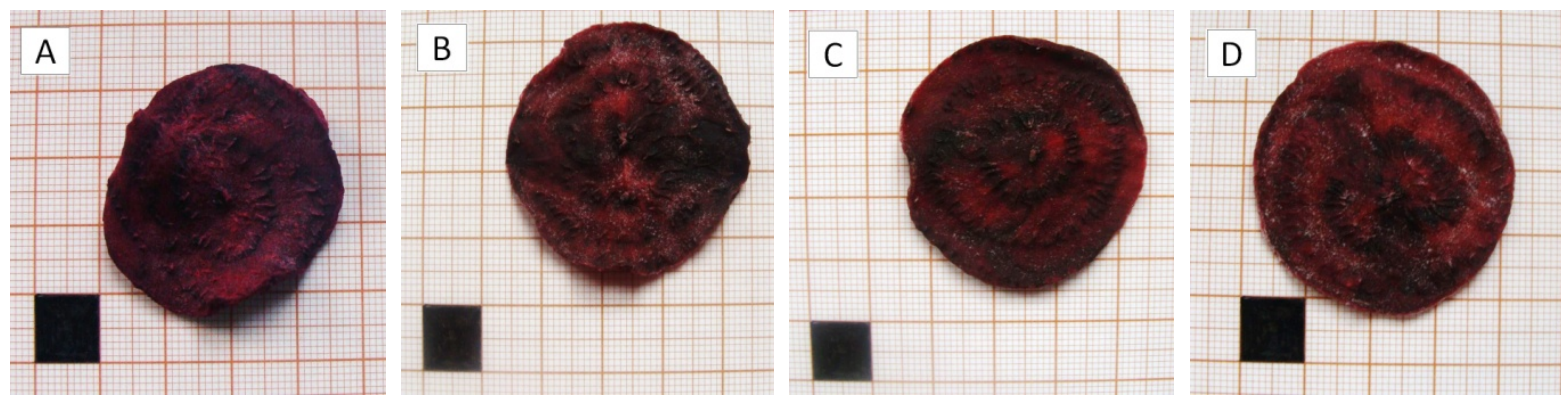

Fig. 9. Photos of red beetroot samples after convective drying with and without $O D$ in the $50 \%$ sucrose solution and different $O D$ times: A) without $O D$, B) $30 \mathrm{~min} O D$, C) $60 \mathrm{~min} O D$, D) $90 \mathrm{~min} O D$

Table 4. Colorimetric data of beet root samples

\begin{tabular}{|c|c|c|c|c|c|c|c|c|c|c|}
\hline$S C[\%]$ & \multicolumn{3}{|c|}{20} & \multicolumn{3}{|c|}{35} & \multicolumn{3}{|c|}{50} & \multirow{2}{*}{$C V$} \\
\hline Time $O D$ & $30 \mathrm{~min}$ & $60 \mathrm{~min}$ & $90 \mathrm{~min}$ & $30 \mathrm{~min}$ & $60 \mathrm{~min}$ & $90 \mathrm{~min}$ & $30 \mathrm{~min}$ & $60 \mathrm{~min}$ & $90 \mathrm{~min}$ & \\
\hline$\Delta L$ & -10.36 & -35.57 & -31.24 & -20.97 & -21.99 & -12.71 & -20.13 & -25.61 & -18.63 & -23.19 \\
\hline$\Delta a$ & 3.52 & 5.66 & 3.09 & 5.38 & 5.14 & 5.94 & 6.45 & 5.26 & 5.27 & 5.07 \\
\hline$\Delta b$ & 7.24 & -15.29 & -8.92 & -1.11 & 1.07 & 3.64 & 2.38 & 4.80 & -3.59 & -10.65 \\
\hline$\Delta E$ & $\begin{array}{r}13.12 \\
\pm 0.67\end{array}$ & $\begin{array}{c}39.13 \\
\pm 0.59 \\
\end{array}$ & $\begin{array}{c}32.64 \\
\pm 0.55\end{array}$ & $\begin{array}{l}21.67 \\
\pm 0.51\end{array}$ & $\begin{array}{c}22.61 \\
\pm 0.51\end{array}$ & $\begin{array}{r}14.49 \\
\pm 0.54 \\
\end{array}$ & $\begin{array}{r}21.27 \\
\pm 0.51\end{array}$ & $\begin{array}{c}26.58 \\
\pm 0.53\end{array}$ & $\begin{array}{r}19.69 \\
\pm 0.53 \\
\end{array}$ & $\begin{array}{c}26.01 \\
\pm 0.60 \\
\end{array}$ \\
\hline
\end{tabular}
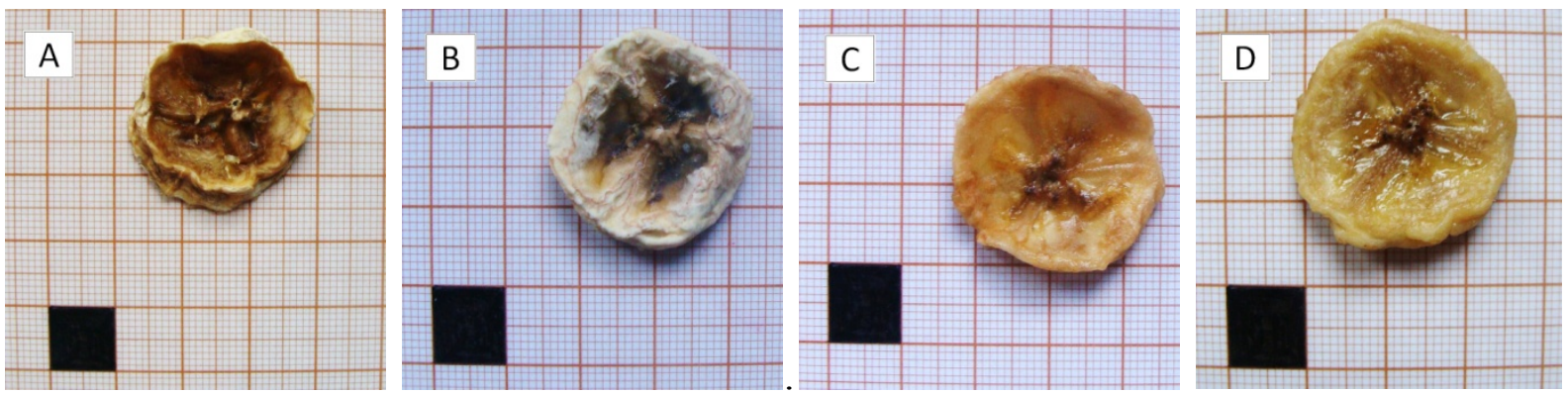

Fig. 10. Photos of banana samples after convective drying with and without $O D$ for 90 min in fructose solution of different concentrations: A) without $O D$, B) $20 \% \mathrm{FR}$, C) $35 \% \mathrm{FR}, \mathrm{D}) 50 \% \mathrm{FR}$
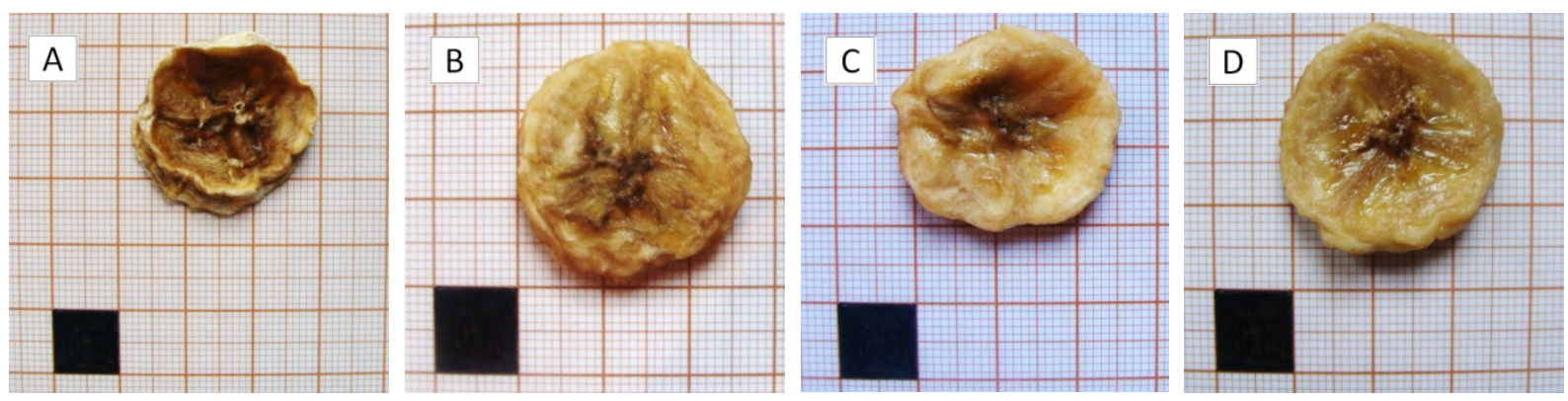

Fig. 11. Photos of banana samples after convective drying with and without $O D$ in $50 \%$ fructose solution and different times of $O D:$ A) without $O D$, B) $30 \min O D$, C) $60 \min O D$, D) $90 \min O D$

The data presented in Table 4 show that the differences between colour parameters for samples with and without $O D$ are rather significant. In the case of samples with $O D$ the differences are also visible between samples of different $O D$ times and concentrations of the solutions. The value of parameter $\Delta L$ 
is particularly high in this case. It is responsible for the sample darkening. The best results were obtained for $O D$ samples with the solution of $50 \%$ concentration for $90 \mathrm{~min}$. Acceptable are also results for the solution of $35 \%$ concentration for $90 \mathrm{~min}$ and for the solution of $20 \%$ for $30 \mathrm{~min}$ of osmotic dehydration.

Figure 10 shows photos of the banana samples after convective drying and without $O D$ for 90 minutes in different concentrations of the osmotic solution. These photographs show that the higher concentration of the solution the better shape and appearance of the dried banana samples. Figure 11 presents photographs of the banana samples for different times of osmotic dehydration at $50 \%$ solution of fructose.

The appearance of the samples with osmotic pretreatment was compared with that after pure convective drying (Fig. 11A). It can be seen that the osmotically dehydrated samples which were next subjected to convective drying are less deformed and look better than the samples subjected to convective drying only.

\section{CONCLUSIONS}

Results gained from convective drying of fruits and vegetables with osmotic preliminary treatment allow to state that although preliminary osmotic dehydration improves significantly the quality of these biological products, it does not shorten significantly the drying time. A shortening of the drying time can be achieved only through elongation of the osmotic dewatering time and an increase of the solution concentration.

Long-lasting $O D$ is characterised by the so-called Solids Gain $(S G)$, which results in diffusion of the sugar dissolved in the hypertonic solutions into the dehydrated samples. This phenomenon may cause partial "sticking" of pores in the dehydrated material, which increases resistivity in the moisture outflow during convective drying.

In some cases, after $O D$ in solutions of high concentration, it was observed that the drying time was shorter than that without preliminary osmotic processing. In this case the osmotic dehydration rate was faster than the diffusion of sugars from solution to dehydrated materials. The best values of the osmotic dehydration parameters such as $W L, S G$ and $W R$ were gained for the beetroot immersed in $50 \%$ solution for 90 minutes, and amounted accordingly to $W L=32.50, \mathrm{SG}=3.93$ and $W R=28.57$. Similarly, the best values of these parameters for the banana were obtained for the samples immersed also in $50 \%$ sucrose solution for 90 minutes and amounted to $W L=55.25, S G=7.70$ and $W R=47.54$.

We can state that preliminary osmotic dehydration limits significantly colour changes of dried samples. The higher concentration of the hypertonic solution and the longer dehydration time the smaller degree of shrinkage and deformations of the sample shape was observed, both for the red beetroot and for the banana.

This work was carried out as a part of the research project 32-127/12 DS-BP sponsored by Poznan University of Technology.

\section{SYMBOLS}

a CIELab colour space parameter

$b \quad$ CIELab colour space parameter

CV convective drying 


$\begin{array}{ll}l & \text { lightness of the colour (in CIELab) } \\ m & \text { mass, } \mathrm{g} \\ m_{d} & \text { mass of dry sample, } \mathrm{kg} \\ m_{i} & \text { initial sample mass. } \mathrm{kg} \\ m_{t}(t) & \text { actual total sample mass, } \mathrm{kg} \\ m_{0} & \text { sample mass after osmotic dehydration, } \mathrm{kg} \\ M & \text { mass of sample solid after osmotic dehydration, } \mathrm{kg} \\ M C & \text { moisture Content (wet basis), } \mathrm{kg} / \mathrm{kg} \\ O D & \text { osmotic dehydration } \\ S G & \text { solids gain, \% } \\ W L & \text { water loss, \% } \\ W R & \text { weight reduction, } \% \\ \Delta E & \text { relative colour change parameter } \\ & \\ \text { Superscripts } & \\ d & \text { dry } \\ i & \text { initial } \\ M & \text { moisture } \\ t & \text { time }\end{array}$

\section{REFERENCES}

Chavan U.D., Prabhukhanolkar A.E., Pawar V.D., 2010. Preparation of osmotic dehydrated ripe banana slices. J. Food Sci. Technol., 47, 380-386. DOI: 10.1007/s13197-010-0063-8.

Chua K.J., Chou S.K., Mujumdar A.S., Ho J.C., Hon C.K., 2004. Radiant-convective drying of osmotic treated agro-products effect on drying kinetics and product quality. Food Control, 15, 145-158. DOI: 10.1016/S09567135(03)00026-4.

Fagunwa A.O., Koya O.A., Faborode M.O., 2009. Development of an intermittent solar dryer for cocoa beans. Agric. Eng. Int.: CIGR Ejournal. XI, manuscr. no. 1292.

Fernandes F.A.N., Rodrigues S., Gaspareto O.C.P., Oliveira E.L., 2006. Optimization of osmotic dehydration of bananas followed by air-drying. J. Food Eng., 77, 188-193. DOI: 10.1016/j.jfoodeng.2005.05.058.

Figiel A., 2010. Drying kinetics and quality of beetroots dehydrated by combination of convective and vacuummicrowave methods. J. Food Eng., 98, 461-470. DOI: 10.1016/j.jfoodeng.2010.01.029.

Gokhale S.V., Lele S.S., 2011. Dehydration of red beet root (Beta vulgaris) by hot air drying process optymization and mathematical modelling. Food Sci. Biotechnol., 20, 955-964. DOI: 10.1007/s10068-011-01324.

Gokhale S.V., Lele S.S., 2012. Optimization of convective dehydration of beta vulgaris for color retention. Food Bioprocess Technol., 5, 868-878. DOI: 10.1007/s11947-010-0359-8.

Kadam D. M., Dhingra D., 2009 Mass transfer kinetics of banana slices during osmo-convective drying. J. Food Proc. Eng. DOI: 10.1111/j.1745-4530.2009.00373.x.

Kowalska H., Lenart A., 2001. Mass exchange during osmotic pretreatment of vegetables. J. Food Eng., 49, 137-140 DOI: 10.1016/S0260-8774(00)00214-4.

Kowalski S.J., Mierzwa D., 2011. Influence of preliminary osmotic dehydration ondrying kinetics and final quality of carrot. Chem. Process Eng., 32, 185-194 DOI: 10.2478/v10176-011-0014-6.

Kowalski S.J., Mierzwa D., Śronek B., 2009. Drying of osmotically dehydrated biological materials. Chem. Process Eng., 30, 559-568.

Li W., Shao Y., Chen W., Jia W., 2011. The effects of harvest maturity on storage quality and sucrosemetabolising enzymes during banana ripening. Food Bioprocess. Technol., 4,1273-1280 DOI: 10.1007/s11947009-0221-z.

Loginova K.V., Lebovka N.I., Vorobiev E., 2011. Pulsed electric field assisted aqueous extraction of colorants from red beet. J. Food. Eng., 106, 127-133 DOI: 10.1016/j.jfoodeng.2011.04.019. 
Manivannan P., Rajasimman M., 2009. Optimization of process parameters for the osmotic dehydration of beetroot in sugar solution. J. Food Eng., 34, 804-824 DOI: 10.1111/j.1745-4530.2009.00436.x.

Menezes E.W. Tadini C.C., Tribess T.B., Zuleta A., Binaghi J., Pak N., Vera G., Dan M.C.T., Bertolini A.C., Cordenunsi B.R., Lajolo F.M., 2011. Chemical composition and nutritional value of unripe banana flour (Mussa acuminata, var. Nanicão). Plant Foods Hum. Nutr., 66, 231-237. DOI: 10.1007/s11130-011-0238-0.

Mujumdar A.S. (Ed.), 2007. Handbook of industrial drying. Third edition, Taylor \& Francis Group, New York.

Mujumdar A.S., Law C.L., 2010. Drying technology: Trends and applications in postharvest processing. Food Bioprocess. Technol., 3, 843-852. DOI: 10.1007/s11947-010-0353-1.

Nastaj J., Witkiewicz K., 2004. Theoretical analysis of vacuum freeze drying of biomaterials at contact-radiantmicrowave heating. Chem. Process Eng., 25, 505-525.

Pabis S., 1999. The initial phase of convection drying of vegetables and mushrooms and the effect of shrinkage. J. Agric. Eng. Res., 72, 187-195. DOI: 10.1006/jaer.1998.0362.

Pabis S., Jaros M., 2002. The first period of convection drying of vegetables and the effect of shape-dependent shrinkage. Biosyst. Eng., 81, 201 - 211. DOI: 10.1006/bioe.2001.0015.

Pakowski Z., Adamski R., 2007. The comparison of two models of convective drying of shrinking materials using apple tissue as an example. Drying Technol., 25, 1139-1149. DOI: 10.1080/07373930701438428.

Pan Y.K., Zhao L.J., Zhang Y., Chen G., Mujumdar A.S., 2003. Osmotic dehydration pretreatment in drying of fruits and vegetables. Drying Technol., 21, 1101-1114. DOI: 10.1081/DRT-120021877.

Patkai G., Barta J., Varsanyi I., 1997. Decomposition of anticarcinogen factors of the beetroot during juice and nectar production. Cancer Letters, 114, 105-106. DOI: 10.1016/S0304-3835(97)04636-3.

Piasecka E., Uczciwek M., Klewicki R., Konopacka D., Mieszczakowska-Frąc M., Szulc M., Bonazzi C., 2012. Effect of long-time storage on the content of polyphenols and ascorbic acid in osmo-convetively dried and osmo-freeze-dried fruits. J. Food Proces. Preserv., 1745-4549. DOI: 10.1111/j.1745-4549.2011.00637.x.

Potter J.D., 1997. Cancer prevention: Epidemiology and experiment. Cancer Letters, 114, 7-8. DOI: 10.1016/S0304-3835(97)04615-6.

Sagar V.R., Suresh Kumar P., 2010. Recent advantages in drying and dehydration of fruits and vegetables: A review. J. Food Sci. Technol., 47, 15-26. DOI: 10.1007/s13197-010-0010-8.

Witrowa-Rajchert D., Rząca M., 2009. Effect of drying method on the microstructure and physical properties of dried apples. Drying Technol., 27, 903-909. DOI: 10.1080/07373930903017376.

Received 03 July 2012

Received in revised form 10 October 2012

Accepted 21 October 2012 